DPM

15,1

178

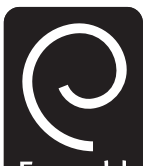

Emerald

Disaster Prevention and Management Vol. 15 No. 1, 2006

pp. $178-189$

(C) Emerald Group Publishing Limited 0965-3562

DOI $10.1108 / 09653560610654329$

\section{Warning for the 26 December 2004 tsunamis}

\author{
Ilan Kelman
}

Center for Capacity Building, National Center for Atmospheric Research, Boulder, Colorado, USA

\begin{abstract}
Purpose - To investigate whether or not people at risk from the 26 December 2004 tsunamis could have had better warning of the event.

Design/methodology/approach - This paper examines short-term actions related to warning following the earthquake and long-term actions related to setting up an Indian Ocean tsunami warning system prior to the disaster. The evidence is presented in the context of the long-term processes needed to create and maintain successful warning systems.
\end{abstract}

Findings - The evidence shows that, based on the knowledge and procedures existing at the time, any expectation of effective warning prior to the tsunamis was unreasonable. On 26 December 2004, as much action was taken as feasible. Prior to the catastrophe, the Indian Ocean tsunami risks were acknowledged but no warning systems were implemented because other priorities were deemed to be higher.

Research limitations/implications - This paper presents a snapshot of the complex issue of warning system development and implementation. Each national and regional case study deserves detailed attention. Further work would add to a more complete understanding of conditions before 26 December 2004.

Practical implications - This case study provides a reminder that planning for warnings must be done before extreme events, not following them. Successful warning systems require investment in a long-term, ongoing process involving pre-event planning, education, and awareness.

Originality/value - This paper provides an initial attempt at evaluating Indian Ocean tsunami warnings on 26 December 2004.

Keywords Tidal waves, South East Asia, Risk intelligence

Paper type Case study

\section{Introduction}

Following the 26 December 2004 tsunamis around the Indian Ocean, much media attention focused on why appropriate warnings had not been provided to reduce loss of life. A search for who could or should be blamed for the deaths was also undertaken. For example, on 4 March 2005, the Pacific Tsunami Warning Center (PTWC) in Hawaii was named in a lawsuit filed by tsunami survivors and relatives of tsunami victims who were suggesting that PTWC should have given more warning (Crabb, 2005). Media coverage and court cases, though, do not always examine the wider and deeper contexts which tend to be root causes of a disaster.

Professor Eve Gruntfest provided essential advice, guidance, and sources. Julie Demuth significantly improved the paper's clarity and writing. Dr Tad Murty, Professor S.K. Dube, and Dr A.E. Muthunayagam kindly described their involvement in developing a tsunami early warning system for India. The Editor and a reviewer provided helpful suggestions which improved this paper. The National Center for Atmospheric Research is supported by the National Science Foundation. 
After a disaster, it is usual to enquire what could have been done differently to reduce the event's consequences. Such enquiries frequently address short-term issues, for instance:

- individual and institutional reactions following the hazard event; and

- the state of the physical environment or social vulnerability just prior to the disaster.

Longer-term aspects tend to receive less attention. Examples are the historical context, social conditions, societal decisions, and governance processes in the decades before the hazard event which, over the long-term, created the state of vulnerability exposed by the disaster (Lewis, 1999; Wisner et al., 2004). While long-term analyses can identify root causes, short-term analyses can lead to unsubstantiated criticism or overzealous blame which can be counterproductive and which can undermine progress in disaster risk reduction.

This paper investigates whether or not people at risk from the 26 December 2004 tsunamis could have had better warning of the event. The evidence is divided into two categories:

(1) Short-term action: after the earthquake, could available information have been better used to issue warnings? Would such warnings have likely reduced the loss of life?

(2) Long-term action: prior to 26 December 2004, how were Indian Ocean tsunamis and the potential for related warning systems being discussed? Why was limited action taken as a result of these discussions?

The main focus is to examine material that had been available before the disaster's scale became apparent, i.e. when the disaster could potentially have been averted, rather than to analyse the post-disaster response and calls for warning improvement. This analysis is important to encourage action long before a disaster strikes, rather than simply reacting to events after they have occurred.

\section{Short-term action: 26 December 2004}

The warning literature (Handmer, 2000; ITS, 2001; Mileti, 1999; Rohrmann, 2000; Sorenson, 2000) illustrates that successful warning systems must complete several complex tasks. For tsunamis, the steps are:

(1) identifying that an event has occurred which might cause a tsunami, usually volcanic activity, an earthquake, or a landslide but also including a strike by an extraterrestrial object such as a meteorite or comet;

(2) observing or calculating that a tsunami has been generated;

(3) mapping the tsunami's projected path;

(4) identifying populated locations which might be inundated by the tsunami;

(5) informing officials in those locations that a warning should be issued;

(6) issuing appropriate warnings through various channels; and

(7) ensuring appropriate and timely responses to the warnings.
Warning for the 26 December 2004 tsunamis 
DPM

15,1

180

To save lives in tsunamis, these steps must occur within a time period of minutes to hours and require detailed and complex science and communication.

For the tsunami-generating earthquake on 26 December 2004, Step 1 involved seismic monitoring stations identifying within minutes the earthquake's approximate location, magnitude, and intensity. The initial information received by PTWC suggested that the earthquake had a moment magnitude of 8.0 (PTWC, 2004a). Within 15 minutes of the shaking, PTWC issued a tsunami warning bulletin stating that no tsunami threat to the Pacific was expected. Nearly an hour later, the earthquake's moment magnitude was revised to 8.5 and PTWC issued a second tsunami warning bulletin (PTWC, 2004b) reiterating that no Pacific tsunami threat was expected but noting that a tsunami might be possible near the epicentre.

Either moment magnitude would indicate a powerful earthquake, but would not inevitably generate large tsunamis. Three days earlier, on 23 December 2004, a moment magnitude 8.1 earthquake with a depth of 10 kilo meter struck south of New Zealand, near Macquarie Island, generating only small tsunamis (USGS NEIC, 2005). Three months later, on 28 March 2005, a moment magnitude 8.7 earthquake with a depth of 30 kilo meter near the location of the 26 December 2004 event also caused only relatively small tsunamis (USGS NEIC, 2005). The 26 December 2004 tremor is now listed as moment magnitude 9.0 at 30 kilo meter depth (USGS NEIC, 2005) which has ten times the amplitude and approximately 31 times the energy release as the preliminary 8.0 estimate.

Given the information available at the time, could and should PTWC have issued stronger and quicker warnings for a potential Indian Ocean tsunami? PTWC (2005) describes their mandate:

The operational objective of the TWS [Tsunami Warning System] in the Pacific is to detect and locate major earthquakes in the Pacific region, to determine whether they have generated tsunamis, and to provide timely and effective tsunami information and warnings to the population of the Pacific to minimize the hazards of tsunamis, especially to human life and welfare. To achieve this objective, the TWS continuously monitors the seismic activity and ocean surface level of the Pacific Basin.

Other operational tsunami warning centres include the West Coast/Alaska Tsunami Warning Center, the Yuzhno-Sakhalinsk Tsunami Warning Center, the Japanese Meteorological Agency's tsunami warning system, and the Puerto Rico Tsunami Warning and Mitigation Program (which ended on 31 December 2004). As with PTWC, the Indian Ocean is not included in the mandates of any of these warning centres.

The possibility existed for the tsunami warning centres to step outside of their mandates in order to issue warnings to Indian Ocean countries. Even without Step 2 confirmed, Steps 3-5 could have been followed as best as feasible under the circumstances.

Tsunami generation and propagation, though, are complex (Braddock, 2003; Kowalik, 2002). The Indian Ocean lacked tsunami-monitoring instruments and tsunami generation and propagation models. That was a significant barrier to understanding what might have been happening and hence formulating appropriate warnings for specific locations (Steps 2-5). Erring on the side of caution, an assumption could have been made that all coastal areas around the Indian Ocean should be warned. For example, Step 2 was covered when internet media reports from Thailand and Indonesia started describing major inundation. 
PTWC has, therefore, been criticised for not phoning the media to issue warnings immediately after the 26 December 2004 earthquake (e.g. http://tsunamilessons. blogspot.com) and for not phoning authorities in countries such as Sri Lanka after internet reports emerged of tsunamis (Chossudovsky, 2004). Government scientists are rarely expected to act on the spur of the moment outside of their mandate and expertise based on internet news reports without adequate data. Anyone around the globe including people in countries yet to be affected - who saw the internet news reports of the unfolding catastrophe on 26 December 2004 had as much information on the tsunamis and had as much authority to contact Indian Ocean country governments as PTWC and the other tsunami warning centres.

As verifiable evidence increased of tsunami destruction in countries such as Thailand and Sri Lanka, PTWC had enough information to take action (NOAA, 2005 provides a timeline of PTWC actions on 26 December 2004, but many of the specific times are unconfirmed and so they are not reproduced here). PTWC contacted the US State Department in order to inform Indian Ocean governments of the tsunami threat through American embassies. NOAA (2005) states that Madagascar and Mauritius were informed in this manner. IOC (2005a) states that these warnings were also given to national authorities in Kenya, Tanzania, and the Seychelles who improvised warning dissemination, significantly reducing the death toll. In contrast, Somalia lacked a central government and several hundred people perished.

The East African experience illustrates that, even if Step 5 had been reached, no guarantee exists that Steps 6-7 would have worked. Even reaching Step 5 would have involved a long series of rapid assumptions for which supporting evidence did not exist until several hours after the earthquake, when many countries' coastlines had already been inundated.

The implications of PTWC suddenly acting outside of its mandate without governmental support - which was obtained before contacting East Africa - should also be considered. If PTWC had unilaterally contacted other countries and no major tsunamis had occurred, political fallout could have been extensive. A major incident could have significantly harmed PTWC and its scientists' credibility, potentially leaving the Pacific as vulnerable to tsunamis as the Indian Ocean countries were.

Following a disaster, suggestions are often made that options should have been available to overcome the difficulties outlined above. Such statements do not indicate that mistakes were made on the day of the event, but do indicate that improvements should have been made before the event. Similarly, for Indian Ocean tsunami warning, the discussion here indicates that improvements are needed, but based on the knowledge and procedures existing at the time, it appears as if little more could have been done to issue successful warnings after the earthquake.

\section{Before 26 December 2004}

Table I summarises the discussion here regarding Indian Ocean tsunamis and warning before 26 December 2004.

\section{Before 26 December 2004: Indian Ocean tsunamis}

The Indian Ocean does not experience large tsunamis frequently, but the threat has been identified (Bryant, 2001; Lander et al., 2003; Murty and Bapat, 1999). In 1883, eruptions from the volcano Krakatoa, Indonesia generated tsunamis which crossed the

\section{Warning for the 26 December 2004 tsunamis}

181 
DPM

15,1

182

Table I.

Summary of discussion regarding Indian Ocean tsunamis and warning before 26 December 2004

\begin{tabular}{lll}
\hline Issue & $\begin{array}{l}\text { Arguments favouring an Indian } \\
\text { Ocean tsunami warning system }\end{array}$ & $\begin{array}{l}\text { Arguments opposing an Indian } \\
\text { Ocean tsunami warning system }\end{array}$ \\
\hline $\begin{array}{l}\text { Knowledge of Indian Ocean } \\
\text { tsunamis }\end{array}$ & $\begin{array}{l}\text { A detailed history exists of } \\
\text { Indian Ocean tsunamis }\end{array}$ & $\begin{array}{l}\text { Life-threatening Indian Ocean } \\
\text { tsunamis occur far less frequently } \\
\text { than other life-threatening events }\end{array}$ \\
$\begin{array}{ll}\text { Initiatives around the } \\
\begin{array}{l}\text { Indian Ocean to implement } \\
\text { a tsunami warning system }\end{array}\end{array}$ & $\begin{array}{l}\text { Some individuals, institutions, } \\
\text { and countries felt that a tsunami } \\
\text { Warning system was needed }\end{array}$ & $\begin{array}{l}\text { Other issues were deemed to be a } \\
\text { higher priority }\end{array}$ \\
$\begin{array}{l}\text { A tsunaming warning system could } \\
\text { long-term processes }\end{array}$ & $\begin{array}{l}\text { contribute to other needed areas } \\
\text { in development and } \\
\text { sustainability, including disaster and social attention spans } \\
\text { risk reduction }\end{array}$ & $\begin{array}{l}\text { might not be sufficient to produce } \\
\text { and maintain an effective warning } \\
\text { system }\end{array}$ \\
& & \\
& &
\end{tabular}

Indian Ocean (Pararas-Carayannis, 2003). In 1945, an earthquake in the Arabian Sea, offshore of Pakistan, caused tsunamis which killed hundreds, many along India's west coast, and which propagated into the Indian Ocean. A 1983 Indian Ocean earthquake hit Diego Garcia with a 1.5 meter wave and the Seychelles with a 0.4 meter wave. NGDC (2005) lists 30 tsunamis around the Indian Ocean during the twentieth century, although the maximum height above sea level is not listed for the majority of events. Information availability, including historical knowledge, does not necessarily imply either awareness of potential threats or interest or ability to counter those threats. Was knowledge about Indian Ocean tsunamis translated into consideration of a tsunami warning system?

\section{Before 26 December 2004: Indian Ocean tsunami warning systems}

Before 26 December 2004, some agencies were actively trying to develop tsunami warning systems in some sectors of the Indian Ocean. For example, the Intergovernmental Oceanographic Commission, the Indian government, and the Indonesian government were pursuing an Indian Ocean tsunami warning system, but were unable to obtain adequate resources.

\section{Intergovernmental Oceanographic Commission}

IOC (1997a) notes that a report concerning an eastern Indian Ocean tsunami warning system was prepared for them, but no action resulted. IOC's (1997b) Annual Report highlights the need for tsunami warning systems outside of the Pacific. IOC (1999) mentions tsunami warning for the eastern Indian Ocean:

Southeast Asia, the southwest Pacific, and Central and South America have no regional tsunami warning centers. Yet these areas are extremely vulnerable... Outside the Pacific region no tsunami warning centers exist, although the tsunami hazard exists on both sides of the Atlantic Ocean, in the eastern Indian Ocean, and in the Mediterranean, Caribbean, and Black Seas. Efforts to establish warning centers in those areas should be encouraged and ITSU [Tsunami Warning System in the Pacific] should provide information and guidance based on its accomplishments and many years of experience in the Pacific.

IOC (2003) noted in its 2004-2005 workplan that they would "support the newly established Working Group on the Tsunami Warning System in the Southwest Pacific 
and Indian Ocean". Recommendation ITSU-XIX.4 in IOC (2003) describes the Working Group on the Tsunami Warning System in the Southwest Pacific and Indian Ocean with $\$ 5,000$ being allocated for each of 2004 and 2005 . This funding is limited, but is reasonable compared to ICG/ITSU's 2004-2005 proposed budget of US $\$ 141,500$. While IOC acknowledged the need for improved international tsunami warnings, including in the Indian Ocean, funding limitations prevented plans from being implemented.

\section{India}

A tsunami warning system was proposed to and accepted by the Indian government prior to 26 December 2004 but had not been implemented due to other priorities. This section relies on personal communications in 2005 from Dr Tad Murty, Professor S.K. Dube, and Dr A.E. Muthunayagam, who are thanked for their time and assistance, but no specific statement should be attributed to any individual because this author has sole responsibility for the content of this paper.

In 1967, the issue of a tsunami warning system for India was raised at the Indian Institute of Science in Bangalore. The idea was supported in principle, but with frequent and severe droughts, river floods, and cyclones causing known levels of destruction, tsunamis were considered to have a lower priority. Further attempts were made to obtain funding for a tsunami warning system in the 1980's, including discussions with the government in New Delhi. Again, the tsunami warning system was considered to be important, but less pressing than other concerns.

In October 1999, a tsunami warning system for India was recommended to the Department of Ocean Development. A detailed planning document was accepted and a budget was committed in India's Tenth Five-Year Plan (Planning Commission, 2002) which started in 2002. Early warnings for disasters are discussed in the Tenth Five-Year Plan, but explicit mention of tsunamis could not be found. Some suggest that the 26 December 2004 tsunamis accelerated, but did not start, the tsunami warning system.

\section{Indonesia}

In 2003, the Indonesian government started developing its National Tsunami Warning System plan with support from the Islamic Development Bank (IOC, 2003). IOC (2003) mentions that it "welcomed the efforts of Indonesia to establish a regional warning system for the Southwest Pacific and Indian Ocean... The Delegate of Australia offered his country's support for the establishment of such a warning system" although no funding is mentioned.

Recommendations from the 2003 International Workshop "Tsunamis in the South Pacific" held in Wellington, New Zealand include:

As Indonesia has recently decided to create a national tsunami warning system, the Workshop recommends that Indonesia and other countries of the South-West Pacific proceed in the development of the Regional Tsunami Warning System for the SW Pacific and Indian Oceans.

\section{Tsunami warning systems elsewhere}

To appreciate the wider context of the low priority for tsunami warning systems prior to 26 December 2004, further information demonstrates that having plans without funding was not unique to the Indian Ocean. For instance, the need for tsunami

\section{Warning for the 26 December 2004 tsunamis}


DPM

15,1

184

warning systems for Central America and the Caribbean had also been discussed (IOC, 1997a, b, 1999, 2003). For Central America, a plan had been designed (Fernandez et al., 1999) but was not implemented. For the Caribbean (Lander et al., 1999), a full plan was developed and CDERA (2004) noted that "The availability of funding will determine how quickly such a system can be implemented". Funding was not available before 2005.

The need for tsunami warning systems in the Indian Ocean and elsewhere had been recognised and some institutions were proceeding as best as feasible given limited resources. Little impetus existed to increase the resources for or prominence of this task.

\section{Before 26 December 2004: warning systems as a long-term process}

Even where warning systems are planned, developed, and funded, successful warnings are challenging because creating and maintaining effective warning systems must occur over the long-term (Glantz, 2003, 2004; Lewis, 1999; Handmer, 2000; Mileti, 1999; Wisner et al., 2004).

For example, PTWC critics (e.g. http://tsunamilessons.blogspot.com; Chossudovsky, 2004) make useful points about improving communications protocols for tsunami warning. They do not fully explain that, to have been successful on 26 December 2004, those protocols should have been developed and implemented long before that day, a process which takes time. The ad hoc East African tsunami warnings on 26 December 2004 emphasise this point. Tsunamis do not always afford the luxuries of several hours of lead-time, a daytime event, and authorities in affected countries willing and able to improvise quickly. The absence of any one of those factors inhibits the success of ad hoc warnings, as was seen in Somalia which lacked authorities. Spending the time to develop desired warning protocols before an urgent situation arises - a long-term process - would yield the best opportunities for successful warnings.

How could warning systems for tsunamis (and other events) be successfully developed, implemented, and maintained? As Glantz (2003, 2004), Lewis (1999), Mileti (1999), and Wisner et al. (2004) note, warning systems should be planned as integrated components of the communities to be warned rather than as top-down impositions from governments or scientists. They should be incorporated into livelihood and development activities and should be continually relevant to the people who will be warned. Again, concerted long-term effort would be required for success.

Specific suggestions for implementing this principle include:

- Recognising that people use a wide range of information sources to create their own warning and response contexts. For example, Dow and Cutter (1998) describe how North Carolinians find sources other than official warnings to be more relevant to their decision-making regarding hurricane evacuation.

- Identifying reasons why people might not wish to heed a warning and trying to allay these concerns before a warning is issued. For example, two reasons why people in Bangladesh did not use flood shelters after warnings were issued were looting fears and worry that they would be charged rent for using the shelters (Haque and Blair, 1992). 
- Ensuring that elements of warning systems are part of people's day-to-day lives rather than being invoked and relevant only when an event threatens. For example, Akhand (1998) describes such aspects for Bangladesh's cyclone warning and shelter system. Wisner et al. (2004) explain how a flood warning system could and should be incorporated into improving water management in Guatemala and Honduras. Johnston et al. (2005) note that pre-existing beliefs must be accommodated to turn tsunami awareness into tsunami preparedness in Washington State, USA.

- Incorporating hazard, vulnerability and warning knowledge into education systems. For example, anecdotes from 26 December 2004 (Cyranoski, 2005) relate instances where an individual's observations of the sea's odd behaviour led to a beach being evacuated just before a tsunami struck. While night-time events would limit use of this specific knowledge, a set of simple observations to which individuals would know how to react would provide a useful tool within early warning systems.

This operational experience with warning systems provides a basis for pursuing the long-term warning system process. Local context must always guide the specific implementation, but some general guidelines emerge:

- Tsunami warning can be effectively linked to warning for other events by using similar, trusted information sources to convey all warnings. As well, reasons why warnings are not reacted to appropriately might be similar for different hazards. Tackling the root cause of those reasons might apply across hazards.

- Warning systems can be integrated into day-to-day activities by making extreme events and their warning one component of wider, ongoing environmental awareness and environmental education. The environment is always changing, with cycles and trends frequently defining possible livelihoods (ISDR, 2005). An understanding of the manner and scope of environmental change at various time and space scales, and adapting livelihoods to these changes, would provide a solid basis for recognising and responding to more extreme or unusual events.

- Maintaining awareness of infrequent events such as tsunamis can usually be achieved by story-telling within the context of the local formal and informal education systems. Chants, dances, textbooks, lectures, sagas, drawings, web sites, interactive seminars, and sculptures are examples of common methods for transferring knowledge to the next generation.

The above points would not necessarily apply everywhere. Methods are not necessarily transferable. The emphasis must be on the local context and needs.

\section{Conclusions: after 26 December 2004}

This paper provides an initial attempt at evaluating whether or not people at risk from the 26 December 2004 tsunamis could have had better warning of the event. Based on the knowledge and procedures existing at the time, any expectation of effective warning after the earthquake but prior to the tsunamis appears to be unreasonable. Before the catastrophe, opportunities to avert a disaster were more available and the risks were acknowledged, but warning systems were not implemented.
Warning for the 26 December 2004 tsunamis

185 
DPM

15,1

186
Since 26 December 2004, tsunami warning systems have had high priority internationally and have been placed in the wider context of global warning systems for events other than tsunamis. Political and financial momentum following the disaster have led to tsunami warning systems moving forward for the Indian Ocean and other locations (IOC, 2005b). As well, the United Nations International Early Warning Programme (ISDR PPEW, 2005) which was proposed in 2003 (EWC II, 2003) is receiving increased support and prominence in the disaster's wake.

Obstacles remain. Some authorities are reluctant to fully share data, such as from real-time seismic monitoring, because of perceived sensitivity of the information. Pledges for funding are not always being fulfilled, especially since 2005 experienced calamities including an earthquake in Kashmir which killed over 70,000 people and the most active Atlantic hurricane season on record. Hurricanes Katrina and Rita along the USA's southern coast and tropical Storm Stan in Central America killed hundreds while exposing warning system challenges similar to the 26 December 2004 tsunamis. Additionally, increased theoretical understanding of warning systems along with further empirical evidence regarding effectiveness would assist in better providing systems which are linked with day-to-day living and which function for several hazards and vulnerabilities.

Although a disaster is frequently required to motivate substantial action for warning systems, a post-event bandwagon is not an excuse to implement inadequate systems, especially those which start only after a hazard event. As Kelman (2005) writes, "Instant tsunami management, just add water and an earthquake' does not work." Instead, investment is required in a long-term, ongoing process combining science, technology, sociology, training, culture, and education - and more.

The aim should be accurate, timely, credible warnings to which people respond with appropriate actions and in a timely fashion. The tasks present immense challenges that must be met in order to reduce losses from future tsunamis and other extreme events.

\section{References}

Akhand, M.H. (1998), "Disaster management and cyclone warning system in Bangladesh", abstract presented at EWCII - Second International Conference on Early Warning, Potsdam, Germany, 11 September.

Braddock, R.D. (2003), "Sensitivity analysis of the tsunami warning potential", Reliability Engineering \& System Safety, Vol. 79 No. 2, pp. 225-8.

Bryant, E. (2001), Tsunami: The Underrated Hazard, Cambridge University Press, Cambridge.

CDERA (2004), Tsunami warning system for the Caribbean, press release, 28 December updated on 5 February 2005, available at: www.cdera.org/cunews/news_releases/article_783.php (accessed 8 February).

Chossudovsky, M. (2004), "Foreknowledge of a natural disaster: Washington was aware that a deadly tidal wave was building up in the Indian Ocean", Centre for Research on Globalisation, 29 December, available at: www.globalresearch.ca/articles/CHO412C.html (accessed 22 August).

Crabb, C. (2005), “Tsunami survivors sue”, Science, Vol. 307, p. 1705.

Cyranoski, D. (2005), “Get off the beach - now!”, Nature, Vol. 433, p. 354.

Dow, K. and Cutter, S.L. (1998), "Crying wolf: repeat responses to hurricane evacuation orders", Coastal Management, Vol. 26, pp. 237-52. 
EWC II (2003), "Effective early warning to reduce disasters: the need for more coherent international action", paper presented at EWC II (Second International Conference on Early Warning), Bonn, 16-18 October 2003, available at: www.ewc2.org/upload/ downloads/EW_programme.pdf (accessed 17 August 2005).

Fernandez, M., Havskov, J. and Atakan, K. (1999), "Destructive tsunamis and tsunami warning in central America”, Science of Tsunami Hazards, Vol. 17 No. 3, pp. 173-85.

Glantz, M.H. (2003), “Usable science 8: early warning systems: do's and don'ts”, report from the workshop held 20-23 October 2003 in Shanghai, China, National Center for Atmospheric Research, Boulder, CO, available at: www.isse.ucar.edu/warning/report.html (accessed 16 August 2005).

Glantz, M.H. (2004), "Usable Science 9: El Niño Early warning for sustainable development in Pacific rim countries and islands", report from the workshop held 13-16 September 2004 on the Galapagos Islands, Ecuador, National Center for Atmospheric Research, Boulder, CO, available at: www.isse.ucar.edu/galapagos/report (accessed 16 August 2005).

Handmer, J. (2000), "Are flood warnings futile? Risk communication in emergencies", The Australasian Journal of Disaster and Trauma Studies, 2000-2002, available at: www. massey.ac.nz/ trauma

Haque, C.E. and Blair, D. (1992), "Vulnerability to tropical cyclones: evidence from the April 1991 cyclone in coastal Bangladesh", Disasters, Vol. 16 No. 3, pp. 217-29.

IOC (1997a), International Co-ordination Group for the Tsunami Warning System in the Pacific, Sixteenth Session, Lima, 23-26 September 1997, IOC/ITSU-XVI/3, ICG/ITSU (International Coordination Group for the Tsunami Warning System in the Pacific), IOC (Intergovernmental Oceanographic Commission), UNESCO (United Nations Educational, Scientific and Cultural Organization), Paris.

IOC (1997b) Annual Report 1997, IOC (Intergovernmental Oceanographic Commission), UNESCO (United Nations Educational, Scientific and Cultural Organization), Paris.

IOC (1999), Tsunami Warning System in the Pacific: Master Plan, 2nd ed., ICG/ITSU (International Coordination Group for the Tsunami Warning System in the Pacific), IOC (Intergovernmental Oceanographic Commission), UNESCO (United Nations Educational, Scientific and Cultural Organization), Paris.

IOC (2003), International Co-ordination Group for the Tsunami Warning System in the Pacific, Nineteenth Session, Wellington, 29 September-2 October, IOC/ITSU-XVI/3, ICG/ITSU (International Coordination Group for the Tsunami Warning System in the Pacific), IOC (Intergovernmental Oceanographic Commission), UNESCO (United Nations Educational, Scientific and Cultural Organization), Paris.

IOC (2005a), "How Kenya, Seychelles avoided tsunami disaster", Information from IOC (Intergovernmental Oceanographic Commission), UNESCO (United Nations Educational, Scientific and Cultural Organization), Paris, available at: http://ioc3.unesco.org/odinafrica/ news.php?offset $=5 \&$ category_no $=0 \& q=\&$ fields $=($ accessed 22 August 2005) .

IOC (2005b), Annex II: Adopted Resolutions from the Twenty-third Session of the Assembly of UNESCO's Intergovernmental Oceanographic Commission, 21-30 June, IOC (Intergovernmental Oceanographic Commission), UNESCO (United Nations Educational, Scientific and Cultural Organization), Paris.

ISDR (2005), Know Risk, Tudor Rose Publications/ISDR (International Strategy for Disaster Reduction), Leicester/Geneva.

ISDR PPEW (2005), The International Early Warning Programme. Brochure from ISDR PPEW (International Strategy for Disaster Reduction Platform for the Promotion of Early

\section{Warning for the 26 December 2004 tsunamis}


DPM

15,1

\section{8}

Warning), Bonn, available at: www.unisdr.org/wcdr/other-meetings/iewp/IEWP-brochure. pdf (accessed 17 August 2005).

ITS (2001), paper presented at US National Tsunami Hazard Mitigation Program Review and International Tsunami Symposium Seattle, WA, 7-10 August 2001, available at: www. pmel.noaa.gov/its2001 (accessed 16 August 2005).

Johnston, D., Paton, D., Crawford, G.L., Ronan, K., Houghton, B. and Bürgelt, P. (2005), "Measuring tsunami preparedness in coastal Washington, United States", Natural Hazards, Vol. 35, pp. 173-84.

Kelman, I. (2005), "Blame who for the tsunami disaster?”, Technical Rescue Magazine, No. 44, Autumn.

Kowalik, Z. (2002), "Relations between tsunami calculations and their physics", abstract presented at the Second Tsunami Symposium, Honolulu, HI, 28-30 May.

Lander, J.F., Whiteside, L.S. and Lockridge, P.A. (2003), "Two decades of global tsunamis 1982-2002”, Science of Tsunami Hazards, Vol. 21 No. 1, pp. 3-88.

Lander, J.F., Whiteside, L.S. and O'Loughlin, K.F. (1999), “Caribbean tsunamis and warning system status", abstract presented at the Tsunami Symposium, Honolulu, HI, 25-27 May.

Lewis, J. (1999), Development in Disaster-Prone Places: Studies of Vulnerability, Intermediate Technology Publications, London.

Mileti, D. and 136 contributing authors (1999), Disasters by Design: A Reassessment of Natural Hazards in the United States, Joseph Henry Press, Washington, DC.

Murty, T. and Bapat, A. (1999), "Tsunamis on the coastlines of India”, Science of Tsunami Hazards, Vol. 17 No. 3, pp. 167-72.

NGDC (2005), "NGDC tsunami database”, NGDC, (National Geophysical Data Center), NOAA (National Oceanic and Atmospheric Administration), Boulder, CO, available at: www. ngdc.noaa.gov/seg/hazard/tsu_db.shtml (accessed 3 August 2005).

NOAA (2005), "NOAA and the Indian Ocean Tsunami", NOAA (National Oceanic and Atmospheric Administration), updated 28 January, available at: www.noaanews.noaa. gov/stories2004/s2358.htm (accessed 3 August 2005).

Pararas-Carayannis, G. (2003), "Near and far-field effects of tsunamis generated by the PAroxysmal eruptions, explosions, Caldera collapses and massive slope failures of the Krakatau volcano in Indonesia on August 26-27, 1883”, Science of Tsunami Hazards, Vol. 21 No. 4, pp. 191-201.

Planning Commission (2002), "10th Five Year Plan (2002-2007) (as approved by the National Development Council)", Planning Commission, Government of India, New Delhi.

PTWC (2004a), “Tsunami bulletin number 001”, PTWC (Pacific Tsunami Warning Center), Ewa Beach, HI, 26 December.

PTWC (2004b), “Tsunami bulletin number 002”, PTWC (Pacific Tsunami Warning Center), Ewa Beach, HI, 26 December.

PTWC (2005), Information from PTWC (Pacific Tsunami Warning Center), available at: www. prh.noaa.gov/ptwc/aboutptwc.htm (accessed 3 August 2005).

Rohrmann, B. (2000), "A socio-psychological model for analyzing risk communication processes", The Australasian Journal of Disaster and Trauma Studies, 2000-2002, available at: www.massey.ac.nz/ trauma

Sorenson, J.H. (2000), "Hazard warning systems: review of 20 years of progress", Natural Hazards Review, Vol. 1 No. 2, pp. 119-25. 
USGS NEIC (2005), Information available at: http://neic.usgs.gov during 2005, USGS NEIC (United States Geological Survey National Earthquake Information Center), Denver, CO.

Wisner, B., Blaikie, P., Cannon, T. and Davis, I. (2004), At Risk: Natural Hazards, People's Vulnerability and Disasters, 2nd ed., Routledge, London.
Warning for the 26 December 2004 tsunamis

189

About the author

Ilan Kelman is a Researcher at the Center for Capacity Building within the National Center for Atmospheric Research in Boulder, Colorado. His main work relates to disaster diplomacy, how disasters do and do not bring together enemy states, and island vulnerability, building safe and healthy communities on small islands and other isolated areas. Ilan Kelman can be contacted at: ilan_kelman@yahoo.com

To purchase reprints of this article please e-mail: reprints@emeraldinsight.com Or visit our web site for further details: www.emeraldinsight.com/reprints 